\title{
The relationship between medical students' epistemological beliefs and achievement on a clinical performance examination
}

\author{
Sun-A Oh${ }^{1}$, Eun-Kyung Chung ${ }^{2}$, Eui-Ryoung $\mathrm{Han}^{3}$, Young-Jong $\mathrm{Woo}^{2}$ and Deiter Kevin ${ }^{4}$ \\ ${ }^{1}$ Department of TESOL, Gwangju University, ${ }^{2}$ Department of Medical Education, Chonnam National University \\ Medical School, ${ }^{3}$ Office of Education and Research, Chonnam National University Hospital, and ${ }^{4}$ Department \\ of Physical Theraphy, Gwangju Health University, Gwangju, Korea
}

Purpose: This study was to explore the relationship between clinical performance examination (CPX) achievement and epistemological beliefs to investigate the potentials of epistemological beliefs in ill-structured medical problem solving tasks.

Methods: We administered the epistemological beliefs questionnaire (EBO) to fourth-year medical students and correlated the results with their CPX scores. The EBO comprised 61 items reflecting five belief systems: certainty of knowledge, source of knowledge, rigidity of learning, ability to learn, and speed of knowledge acquisition. The CPX included scores for history taking, physical examination, and patient-physician interaction.

Results: The higher epistemological beliefs group obtained significantly higher scores on the CPX with regard to history taking and patient-physician interaction. The epistemological beliefs scores on certainty of knowledge and source of knowledge were significantly positively correlated with patient-physician interaction. The epistemological beliefs scores for ability to learn were significantly positively correlated with those for history taking, physical examination, and patient-physician interaction.

Conclusion: Students with more sophisticated and advanced epistemological beliefs stances used more comprehensive and varied approaches in the patient-physician interaction. Therefore, educational efforts that encourage discussions pertaining to epistemological views should be considered to improve clinical reasoning and problem-solving competence in the clinic setting.

Key Words: Clinical competence, Epistemological beliefs, Medical history taking, Physical examination, Physician-patient relations

\section{Introduction}

Epistemological beliefs are fundamental assumptions about the nature of knowledge, the certainty of knowing, the criteria and justifications for knowing. There is a variety of views explaining epistemological beliefs such as developmental, multidimensional, and integrated theoretical models. The model of Perry [1], King \&
Kitchener [2], Baxter Magolda [3] described epistemological developments as a progression, Schommer [4] and Hofer [5] considered multidimensional frameworks of epistemological beliefs. Schommer [4,6] proposed epistemological beliefs consisting of five dimensions: stability of knowledge, structure of knowledge, source of knowledge, speed of knowledge acquisition and control of knowledge acquisition. Hofer [5] indicated four types of beliefs dimensions: knowledge of certainty, source of
Received: November 17, 2015 • Revised: December 7, 2015 • Accepted: December 8, 2015 Corresponding Author: Eun-Kyung Chung (http://orcid.org/0000-0002-3595-0220)

Department of Medical Education, Chonnam National University Medical School, 160 Baekseo-ro, Dong-gu, Gwangju 61469, Korea

Tel: +82.62.220.4178 Fax: +82.62.236.3653 email: ekcmedu@chonnam.ac.kr
Korean J Med Educ 2016 Mar; 28(1): 29-34.

http://dx.doi.org/10.3946/kjme.2016.7

eISSN: 2005-7288

(C) The Korean Society of Medical Education. All rights reserved. This is an open-access article distributed under the terms of the Creative Commons Attribution Non-Commercial License (http:// creativecommons.org/licenses/by-nc/3.0/), which permits unrestricted non-commercial use, distribution, and reproduction in any medium, provided the original work is properly cited. 
knowledge, the simplicity and the justification of knowledge. On the other hand, epistemological belief is an individual presupposition about knowledge and learning which play an influential role on the cognitive process [7]. They presented integrated theoretical model between epistemological beliefs and self-regulated learning $[7,8]$.

Previous educational studies have examined the effects of epistemological beliefs on such areas of learning as reading comprehension [6], text processing [9], conceptual change [10] and multiple decision making [11,12]. On the other hand, instructional contexts could change the students' epistemological beliefs $[13,14]$.

Epstemological beliefs also affect problem-solving skills and strategies in poorly structured environments $[6,15,16]$. Students who had simpler understandings of the structure of knowledge and invariability of knowledge made simpler diagnoses than did those with more complicated understandings. They also ignored divergent and idiosyncratic patient situations in the decisionmaking process [17]. Learners with a belief that knowledge is a fixed entity have been shown to engage in more rapid and superficial learning than thoughtful and deep learning [18]. Schommer \& Dunnell [19] showed the more students had a belief that the ability of learning is decided at birth, learning is quick, and knowledge is unchangeable, the more likely they had an attitude of writing simplistic answers to problems.

Roex \& Degryse [20] described the possible role of epistemological beliefs in medicine as follows: First, the explosive growth in the amount and accessibility of medical information expects the strategies on how to acquire knowledge. Second, ill-structured problem solving often demands solvers to think about various views and apply multiple standards while assessing problems [21,22]. Third, medical practice is a problemsolving process with scientific knowledge. Doctors must understand the origin of the knowledge, integrate new knowledge into existing knowledge and apply the treatment into patient.

Since personal epistemological beliefs affect students' behaviors and learning achievements, medical students' clinical performance examination (CPX) achievements may differ by students' epistemological beliefs stances. We hypothesized that students with naive beliefs such as knowledge is unchangeable and the source of knowledge is from authorities would be less likely to implement effective CPX strategies. Students with sophisticated beliefs about the complexity of knowledge, multiple perspectives on learning, and progressive learning processes would be more likely to apply multifaceted approaches with their patients. Therefore, the purpose of this study was to explore the relationship between medical students' epistemological beliefs and their achievement on the CPX.

\section{Subjcets and methods}

\section{Subjects}

The fourth-year of 130 students at Chonnam National University Medical School participated in this study. Excluding the incomplete data, the data of 124 students were analyzed (response rate, 95.4\%). The Institutional Review Board determined that the study was exempt from the human subjects' research regulations. Consent was obtained from all participants. Seventy-three of the participants $(58.9 \%)$ in this study were male, and 77 (62.1\%) were under the age of 25.

\section{Data collection}

The students' epistemological beliefs were assessed using the Korean version of the Jehng, Johnson, and 
Table 1. Epistemological Beliefs Subscales and Their Reliability

\begin{tabular}{|c|c|c|c|c|}
\hline \multirow{2}{*}{ Subscale } & \multicolumn{3}{|c|}{ Cognitive disposition } & \multirow{2}{*}{ Cronbach o } \\
\hline & Naîve (1 point) & --.-- & Sophisticated (5 point) & \\
\hline Certainty of knowledge & Knowledge is absolute & ----- & Knowledge is tentative & 0.646 \\
\hline Source of knowledge & Knowledge is given by authority & ---- & Knowledge is acquired by the learner & 0.727 \\
\hline Rigidity of learning & $\begin{array}{l}\text { Learning is a process to take } \\
\text { objective knowledge }\end{array}$ & $-\ldots----$ & $\begin{array}{l}\text { Learning is a constructive process to } \\
\text { acquire knowledge by the learner }\end{array}$ & 0.491 \\
\hline Ability to learn & Learning ability is innate & $-\ldots----$ & $\begin{array}{l}\text { Learning ability can be improved over } \\
\text { time and individual effort }\end{array}$ & 0.710 \\
\hline Speed of knowledge acquisition & Learning happens quickly & ------ & Learning happens gradually & 0.622 \\
\hline
\end{tabular}

Anderson's Epistemological Beliefs Questionnaire (EBQ)

[15]. The EBQ comprised 61 items rated on a 5-point Likert scale to reflect five belief systems: certainty of knowledge, source of knowledge, rigidity of learning, ability to learn, and speed of knowledge acquisition (Table 1). Higher scores represent a less dualistic, more relativistic epistemological stance, and lower scores indicate a more dualistic and more objectivist epistemological stance. For example, when a student obtained a low score on the certainty of knowledge, this score reflected the student's belief that knowledge is an absolute and unchanging truth. Students with sophisticated epistemological beliefs regarding the certainty of knowledge believe that knowledge is constantly evolving and that any knowledge is not immutable. The reliability of the whole EBQ was $\alpha=0.853$. The reliability of subscales of epistemological beliefs are described in the Table 1. The students were asked to complete the EBQ, followed by the completion of the CPX.

The CPX consists of six symptoms representing common clinical problems including insomnia, syncope, dyspnea, hematemesis, back pain, and bruising. The students were allowed 10 minutes to interact with the standardized patients (SPs) regarding each symptom and were given another 5 minutes to prepare for the next examination. The SPs rated the patient-physician interaction on a 4-point Likert scale, and the medical faculty assessed the history taking and physical exami- nations using a dichotomous scale for the performance items. The five medical schools constituting the Jeolla Consortium for Clinical Performance Examination developed the cases and checklists and trained the SPs.

\section{Data analysis}

The overall epistemological beliefs scores were stratified into two groups by the mean score, and each CPX raw score was converted to T-scores. Student t-tests were used to identify differences of the CPX category scores according to the epistemological levels. Pearson correlation analyses were used to investigate relationships among CPX category scores and epistemological beliefs subscales scores. All analyses were performed using SPSS software version 18.0 (SPSS Inc., Chicago, USA).

\section{Results}

Table 2 shows differences in CPX category scores with respect to overall epistemological beliefs levels. The higher epistemological beliefs group had significantly higher scores for history taking $(t=2.285, \mathrm{p}=0.024)$ and patient-physician interaction $(t=2.004, p=0.047)$ than did the lower one. No significant differences between higher and lower epistemological beliefs groups were observed with respect to physical examinations. 
Table 2. Difference of Clinical Performance Examination Category Scores by Overall Epistemological Beliefs Levels

\begin{tabular}{|c|c|c|c|c|}
\hline \multirow{2}{*}{ CPX category } & \multicolumn{2}{|c|}{ Overall EB levels } & \multirow{2}{*}{$\mathrm{t}$} & \multirow{2}{*}{$\mathrm{p}$-value } \\
\hline & Lower group $(n=61)$ & Higher group $(n=63)$ & & \\
\hline History taking & $48.76 \pm 6.36$ & $51.22 \pm 5.62$ & 2.285 & 0.024 \\
\hline Physical examination & $49.17 \pm 6.22$ & $50.82 \pm 5.52$ & 1.559 & 0.122 \\
\hline Patient-physician interaction & $48.96 \pm 5.63$ & $51.03 \pm 5.83$ & 2.004 & 0.047 \\
\hline
\end{tabular}

Data are presented as mean \pm standard deviation.

CPX: Clinical performance examination, EB: Epistemological beliefs.

Table 3. Correlations between Epistemological Beliefs Subscale Scores and Clinical Performance Examination Category Scores

\begin{tabular}{lccccc}
\hline \multirow{2}{*}{ CPX category } & \multicolumn{5}{c}{ EB subscale } \\
\cline { 2 - 6 } & $\begin{array}{c}\text { Certainty } \\
\text { of knowledge }\end{array}$ & $\begin{array}{c}\text { Source } \\
\text { of knowledge }\end{array}$ & $\begin{array}{c}\text { Rigidity } \\
\text { of learning }\end{array}$ & Ability to learn & $\begin{array}{c}\text { Speed of knowledge } \\
\text { acquisition }\end{array}$ \\
\hline History taking & 0.154 & $0.174^{*}$ & 0.055 & $0.232^{*}$ & 0.019 \\
Physical examination & 0.173 & 0.136 & 0.109 & $0.224^{*}$ & 0.055 \\
Patient-physician interaction & $0.250^{*}$ & $0.231^{*}$ & 0.109 & $0.225^{*}$ & 0.018 \\
\hline
\end{tabular}

CPX: Clinical performance examination, EB: Epistemological beliefs. ${ }^{*} \mathrm{p}<0.05$ by Pearson correlation analyses.

Statistically significant correlations were found among the epistemological beliefs scales and CPX category scores (Table 3). The score of epistemological beliefs for certainty of knowledge was significantly positively correlated with those for patient-physician interaction $(r=0.250, p=0.005)$. Epistemological beliefs scores for source of knowledge were significantly positively correlated with those for history taking $(\mathrm{r}=0.174, \mathrm{p}=0.050)$ and patient-physician interaction $(r=0.231, p=0.010)$. Epistemological beliefs scores for ability to learn were significantly positively correlated with those for history taking $(\mathrm{r}=0.232, \mathrm{p}=0.010)$, physical examination $(\mathrm{r}=0.224, \mathrm{p}=0.012)$, and patientphysician interaction $(\mathrm{r}=0.225, \mathrm{p}=0.012)$.

\section{Discussion}

The higher epistemological beliefs group had higher achievements for history taking and patient-physician interaction than did the lower one. These results could indicate that students with a sophisticated, less dualistic epistemological beliefs stance performed better on the $\mathrm{CPX}$, especially with respect to history taking and the patient-physician interaction.

There were slightly weak-positive correlations between epistemological beliefs scores on certainty of knowledge and CPX scores measuring patient-physician interaction. The weak-positive correlations were also demonstrated between epistemological beliefs scores on source of knowledge and the CPX scores measuring history taking and patient-physician interaction. Ability to learn was positively correlated with history taking, physical examination, and patient-physician interaction.

Although the correlations with epistemological beliefs and CPX components were not very strong, these results were consistent with the findings of Schommer [6] and Cano [23], which showed that students who believed knowledge is not absolute or acquired in an unmediated fashion attained greater academic success. In poorly structured medical situations, students with simpler 
understandings about the structure of knowledge provided simpler diagnoses than did those who demonstrated more complex thoughts in this regard [17,24,25].

Scores on source of knowledge were related to how students view the patient-physician interaction. Those who had a more developed understanding of the source of knowledge were more likely to question the opinions of authorities when their own understanding differed. These students also paid more sincere attention what their patients were saying, regarding this information as a good source of knowledge. Students should try to identify plausible interpretations of symptoms and signs and could be able to suggest alternative while gathering information from and sharing it with patients.

Additionally, ability to learn of the epistemological beliefs was correlated with physical examination as well as history taking and patient-physician interaction. As physical examination was the item to evaluate the level of technical skills, there might be good results on the behaviors of students who believed the skills and attitude could be enhanced by repetitive practice.

Kienhues et al. [11] investigated how laypersons deal with conflicting versus consistent medical information on the Web. Students with an access to conflicting medical information showed more advanced treatments than those who were provided with well-structured information. Exposure to different ways of thinking could facilitate the beliefs development and may encourage students to become more relativistic and appreciative of multiple perspectives. Our results revealed that more sophisticated and advanced epistemological beliefs were positively related with the clinical performance as the outcomes of learning in medicine. Therefore, educational efforts that encourage discussions pertaining to epistemological views should be considered to improve clinical reasoning and problem-solving competence in the clinical setting.
The limitations of this study should be considered when interpreting the results. First, the correlations between epistemological beliefs and CPX were not strong. Therefore, we should ask more careful interpretations and suggestions on these results. In a further study, various sources would be needed to understand the students' epistemological beliefs such as interviews and writings. Second, our study focused only on the relationship between medical students' epistemological beliefs and their CPX performance. Further research may need to be carried out to determine other factors contributing to CPX performance.

Acknowledgements: None.

Funding: None.

Conflicts of interest: The authors alone are responsible for the content and writing of the article.

\section{References}

1. Perry WG Jr; Harvard University, Bureau of Study Counsel. Forms of intellectual and ethical development in the college years: a scheme. New York, USA: Holt, Rinehart and Winston; 1970.

2. King PM, Kitchener KS. Developing reflective judgment: understanding and promoting intellectual growth and critical thinking in adolescents and adults. San Francisco, USA: Jossey-Bass; 1994.

3. Baxter Magolda MB. Evolution of a constructivist conceptualization of epistemological reflection. Educ Psychol 2004; 39: 31-42.

4. Schommer M. Effects of beliefs about the nature of knowledge on comprehension. J Educ Psychol 1990; 82: 498-504.

5. Hofer BK. Epistemological understanding as a metacogni- 
tive process: thinking aloud during online searching. Educ Psychol 2004; 39: 43-55.

6. Schommer M. Epistemological development and academic performance among secondary students. J Educ Psychol 1993; 85: 406-411.

7. Hofer BK, Pintrich PR. The development of epistemological theories: beliefs about knowledge and knowing and their relation to learning. Rev Educ Res 1997; 67: 88-140.

8. Muis KR. The role of epistemic beliefs in self-regulated learning. Educ Psychol 2007; 42: 173-190.

9. Kardash CM, Howell KL. Effects of epistemological beliefs and topic-specific beliefs on undergraduates' cognitive and strategic processing of dual-positional text. J Educ Psychol 2000; 92: 524-535.

10. Mason L, Boldrin A, Zurlo G. Epistemological understanding in different judgment domains: relationships with gender, grade level, and curriculum. Int J Educ Res 2006; 45: 43-56.

11. Kienhues D, Stadtler M, Bromme R. Dealing with conflicting or consistent medical information on the web: when expert information breeds laypersons' doubts about experts. Learn Instr 2011; 21: 193-204.

12. Bromme R, Thomm E, Wolf V. From understanding to deference: laypersons' and medical students' views on conflicts within medicine. Int J Sci Educ Part B Commun Public Engagem 2015; 5: 68-91.

13. Ozkal K, Tekkaya C, Cakiroglu J, Sungur S. A conceptual model of relationships among constructivist learning environment perceptions, epistemological beliefs, and learning approaches. Learn Individ Differ 2009; 19: 71-79.

14. Rhee JA, Chung EK, Oh SA, Baik YH, Woo YJ. Changes of epistemological beliefs and self-regulated learning in problem-based learning. Korean J Med Educ 2009; 21: 153-161.

15. Jehng JC, Johnson SD, Anderson RC. Schooling and students' epistemological beliefs about learning. Contemp Educ Psychol 1993; 18: 23-35.

16. Shin S, Song HD. Finding the optimal scaffoldings for learners' epistemological beliefs during ill-structured problem solving. Interact Learn Environ. Epub 2015 September 1. http://dx.doi.org/10.1080/10494820.2015.1073749.

17. Spiro RJ, Coulson RL, Feltovich PJ, Anderson DK Cognitive flexibility theory: advanced knowledge acquisition in ill-structured domains. In: Ruddell MR, Ruddell RB, Singer $\mathrm{H}$, eds. Theoretical models and processes of reading. Newark, USA: International Reading Association; 1994. p 602-615.

18. Stipek D, Gralinski H. Children's beliefs about intelligence and school performance. J Educ Psychol 1996; 88: 397-407.

19. Schommer M, Dunnell PA. Epistemological beliefs of gifted high school students. Roeper Rev 1997; 19: 153-156.

20. Roex A, Degryse J. Introducing the concept of epistemological beliefs into medical education: the hot-airballoon metaphor. Acad Med 2007; 82: 616-620.

21. Jonassen DH. Instructional design models for wellstructured and ill-structured problem-solving learning outcomes. Educ Technol Res Dev 1997; 45: 65-94.

22. Angeli C, Valanides N. Epistemological beliefs and illstructured problem-solving in solo and paired contexts. J Educ Technol Soc 2012; 15: 2-14.

23. Cano F. Epistemological beliefs and approaches to learning: their change through secondary school and their influence on academic performance. Br J Educ Psychol 2005; 75(Pt 2): 203-221.

24. Knight LV, Mattick K. 'When I first came here, I thought medicine was black and white': making sense of medical students' ways of knowing. Soc Sci Med 2006; 63: 1084-1096.

25. Spiro RJ, Feltovich PJ, Coulson RL. Two epistemic worldviews: prefigurative schemas and learning in complex domains. Appl Cogn Psychol 1996; 10: 51-61. 